\title{
IMPLEMENTATION OF MOBILE APPLICATION FOR A MUSEUM BY USING INTERNET OF THINGS TECHNOLOGY
}

\author{
Anthony Widjaja, James Purnama, Maulahikmah Galinium \\ Faculty of Engineering and Information Technology, Swiss German University \\ anthony.widjaja@student.sgu.ac.id, james.purnama@sgu.ac.id, maulahikmah.galinium@sgu.ac.id
}

\begin{abstract}
This project is conducted based on the Nawacita policy from President Joko Widodo. Tourists tend to explore the attraction independently instead of using a tour guide, but there are minimum supporting facilities because of the limitations of detailed information on tourist attraction in various languages that are not interesting and less interactive. The objectives of the research are to develop an Internet of Things based mobile application named eTourGuide that uses a location-based service to get information about the content interestingly and interactively inside a museum. The location-based service uses beacon that broadcast Bluetooth Low Energy (BLE) signal. Development of the research includes several experiments for gathering the data optimally. After completing the development, user experience questionnaire is required to evaluate the result of user's experience after using the application. The result shows positive results of user's experience after using the application.
\end{abstract}

Keywords: Tour guide, Internet of Things, Location-Based Service, Museum, Beacon

\section{INTRODUCTION}

The Nawacita policy by President Joko Widodo states that tourism is one of the main priorities in the development of Indonesia, showing that the number of foreign tourists visiting Indonesia is increasing steadily with the development of the tourism sector (Cayo Indonesia, n.d.). Statistics show that from 2014 until 2017, tourist arrivals had increased from around 750.000 to 1.160 .000 tourists. These arrivals have almost doubled since 2014, which proves that tourism in Indonesia is growing continuously (Investment, n.d.).

Many foreign tourists who visit Indonesia may need a tour guide to assist them in doing activities. This happens because of the lack of understanding of Bahasa Indonesia. In fact, a tour guide may be needed because many Indonesian people are still not fluent in English. The Internet of Things (IoT) is being trusted by people because the IoT are using devices that connect through the Internet. IoT has grown because people have limited time and accuracy in acquiring data. IoT provides efficiency because it uses data that has been gathered, so people can track and record it all (IoT Agenda, 2016).

The objectives are to implement a mobile application that uses a location-based service that can make tourists easier to get information about the content inside a museum in multiple languages and to prove that an Internet of Things based mobile application (eTourGuide) can satisfy tourists experience in getting the information interestingly and interactively. On the other hand, the research is

Teknologi Informasi dan Komunikasi 
conducted to improve knowledge of tourists about the information inside the museum and introduce new experience in obtaining the information inside the museum. The Internet of Things (IoT) consists of sensors, devices, networks, and software to exchange or collect the data. The Internet of Things can help to improve efficiency and optimize the system operation from the data that has been gathered. Moreover, The Internet of Things can help to process the data that is gathered to reduce manpower and false information (Gallagher, 2016).

In this implementation of the IoT, the Estimote beacon is used. It can only be used for up to 2 years with the same range up to 70 meters. Estimote has its own SDK called Estimote SDK. Estimote sells this beacon at $\$ 59$ for three devices (Compare Beacon, n.d). iBeacon and Eddystone are the protocol packets that are broadcast from the beacon. iBeacon protocol broadcasts one packet that consist of 16 bytes of Universally Unique Identifier (UUID), 2 bytes of major number, and 2 bytes of minor number (Cucini, et.al, 2016). Eddystone protocol broadcasts three packets format such as, Unique Identifier (UID) consists of 10 bytes of namespace ID, and 6 bytes of instance ID, Ephemeral ID (EID) for security, Uniform Resource Locator (URL) for transmitting an URL, and Telemetry (TLM) for managing the data from the beacon (Barapatre, et.al, 2017).

As related work, there are several museums that use an application using beacons. The beacon is implemented at museum and public garden. All applications provide the features with the advantages of using the beacon. Navajivan Trust Navajivan Trust is a publishing house that runs the museum in India. It uses an Estimote beacon. Their features are push notification, Customer Management System (CMS), and Donation that is conducted through the application. The advantages that are the extended battery life and the beacon is ready to use (Cygnetinfotech, n.d.). The Metropolitan Museum of Art The Metropolitan Museum of Art is in New York, USA. It uses an Estimote beacon. Their features are location context based on the beacon and it provides content with a video inside the application. The advantage is the battery life lasts up to 2 years and the disadvantage that was discovered was temperature changes may affect in battery life (Doljenkova, 2015). The Royal Botanical Gardens
Kew The Royal Botanical Gardens Kew in England and it uses a beacon from Kontakt.io. Their main feature is to deliver the content based on location proximity interactively through an application. The advantage is cheaper price compare to implementing a Wi-Fi (Gasiorek, 2015). Brooklyn Museum Brooklyn Museum is in New York, USA and it uses an Estimote beacon. The feature is to explain the exhibits to visitors. The advantage is it does not need wired connection for implementing this beacon. However, the disadvantage is beacon signal can be disrupted because of the exhibits that may block the signal broadcast (Bernstein, 2015).

In addition to implementation of the application, user experience questionnaire is also conducted to collect feedback after using the application (eTourGuide). The questionnaire called User Experience Questionnaire (UEQ). It allows the user of the application to express or evaluate the application. From 26 items from the original version of the UEQ, there are six scales that are used to evaluate the product: 1) Attractiveness; Overall the impression of the product. Do users like or dislike it? Is it attractive, enjoyable or pleasing? 2) Perspicuity; Is it easy to get familiar with the product? Is it easy to learn? Is the product easy to understand and unambiguous? 3) Efficiency; Can users solve their tasks without unnecessary effort? Is the interaction efficient and fast? Does the product react to user input quickly? 4) Dependability; Does the user feel in control of the interaction? Can he or she predict the system's behavior? Does the user feel confident when working with the product? 5) Stimulation; Is it exciting and motivating to use the product? Is it enjoyable to use? 6) Novelty Is the product innovative and creative? Does it capture the user's attention?

Attractiveness is a pure valence dimension. Perspicuity, Efficiency and Dependability are the aspects of pragmatic quality (goal-directed). On the other hand, Stimulation and Novelty are hedonic quality aspects (not goal-directed). For evaluating the application (eTourGuide), pragmatic quality and hedonic quality are needed to calculate the result of the questionnaire. Hence, the UEQ is shortened to only eight items to evaluate the application (Laugwitz, et.al, 2008) (Schrepp \&Hinderks, 2014) (Schrepp, et.al, 2017a) (Schrepp, et.al., 2017b).

$$
\text { Teknologi Informasi dan Komunikasi }
$$




\section{METHOD}

Figure 1 shows that the implementation begins from finding the suitable beacon among other beacons. After the beacons had been compared, the museum needed to be analyzed for positioning the beacons. Later, the application for mobile phone was created with the development of the prototype. After it was finished, the prototype needed to be demonstrated and improved once the feedback had been gathered. The software and the prototype were improved after the testing had finished.

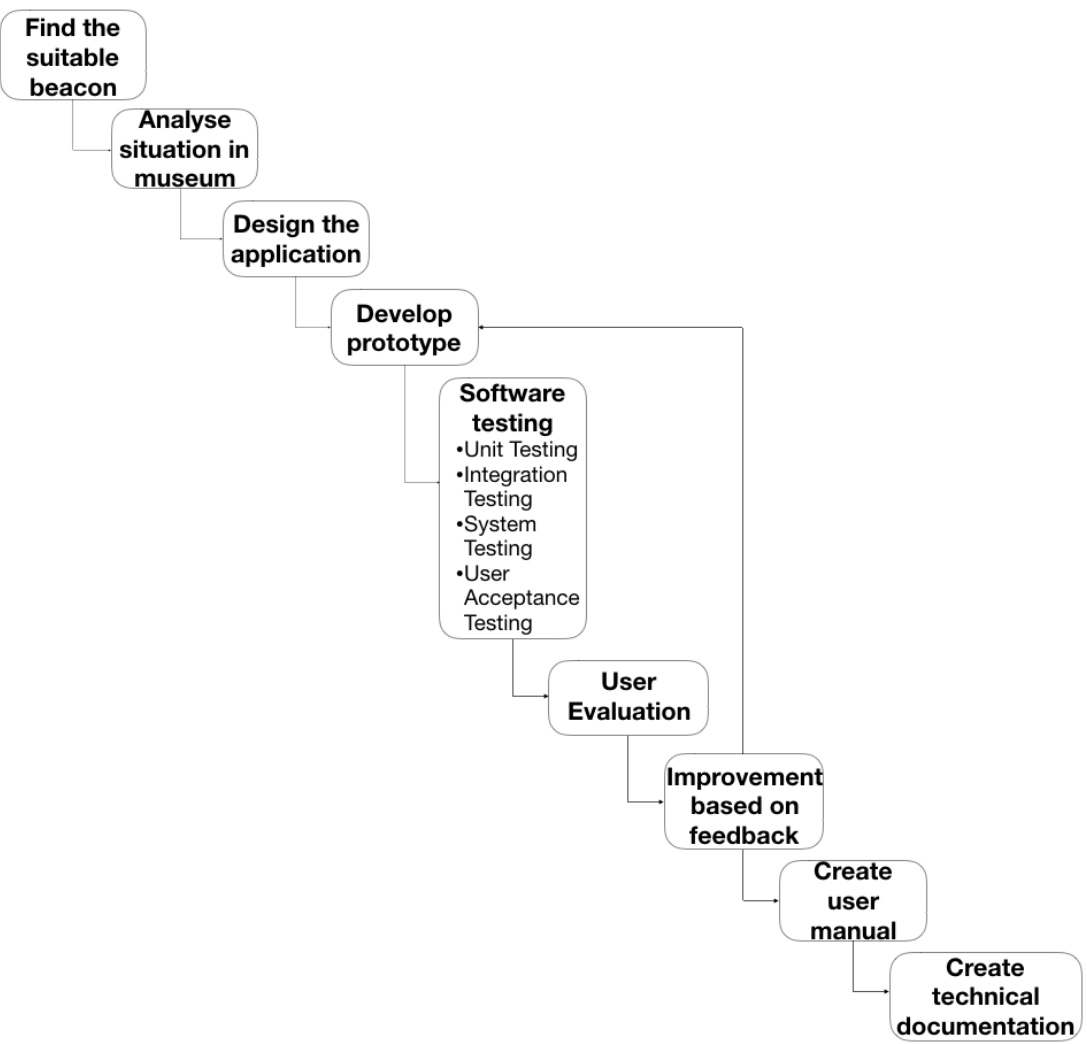

Figure 1 : Software Development Life Cycle

In finding the most suitable beacon, the SDK from each beacon's type is needed to find the most suitable beacon for developing the application. The comparable SDK is from the code implementation, the logic flow of the code, and finding the feature from each SDK. The examples of related works also influence in terms of selection of beacon's type. The method is to conduct an experiment on those SDKs to find the most suitable beacon among others. Furthermore, the observation method is used for analyzing the situation in the museum. The observation is conducted in a museum called Museum Wayang. The observation consists of observing the size of the room, the number of goods, and the layout position of the room. Analyzing the situation is also needed for having the outline of the application design.

Figure 2 shows about the activity that happens from the beginning. Tourist with their Bluetooth and Internet connection on their mobile device opens the application (eTourGuide). Later, the beacon broadcasts the signal, which the mobile device detects signal and the application requests the information to the server based on beacon's ID from the broadcasted signal. The server returns the information to the application to show the information to the visitors or tourists for them to read regarding the information.

Teknologi Informasi dan Komunikasi 


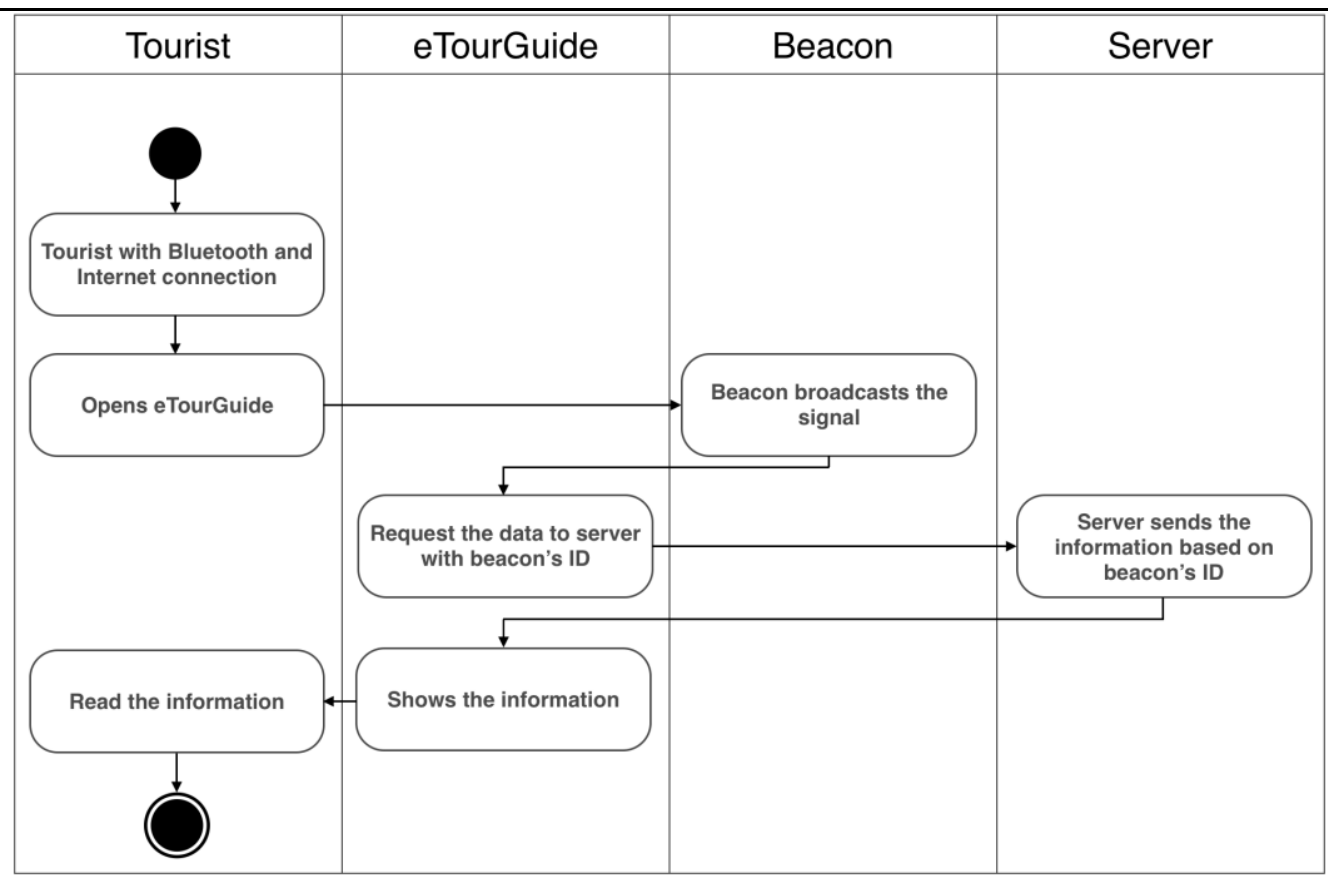

Figure 2 : Overview System Diagram

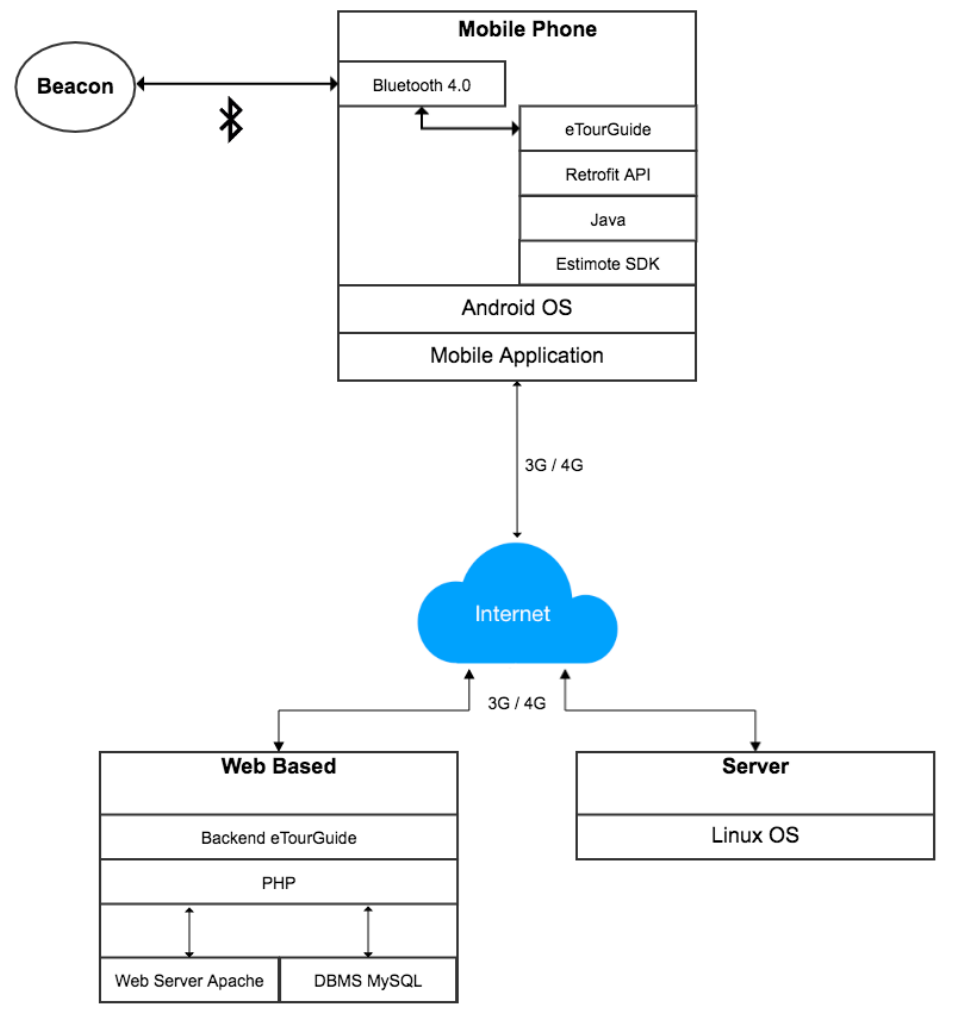

Figure 3 : Architecture Diagram 
Figure 3 shows that the beacon sends the signal to the mobile phone (the application eTourGuide). Android devices with at least Bluetooth 4.0 connection, detects the beacon signal. Later, eTourGuide provides the information related to the objects based on beacon's ID from the server using Internet connectivity. The eTourGuide itself is built from beacon's own SDK. The server runs on Linux OS where the database stores the information about the objects. The backend of eTourGuide with the user experience is built from PHP and Java and using Web Server Apache.
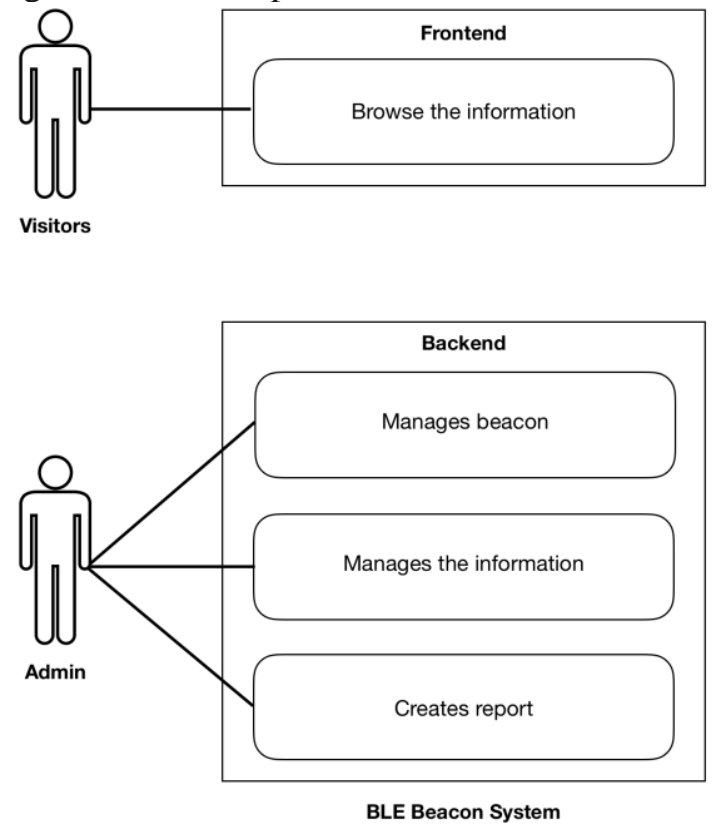

Figure 4 : Use Case Diagram

Figure 4 shows on how the beacon sends the notification signal within a certain time interval. Tourists receives the notification that is sent from beacon and they can browse the information related to the objects. The admin employees need to manage and maintain the beacons and the information related to the objects. Furthermore, developing the prototype for the mobile requires the code editor, which is Android Studio, the SDK from the beacon itself, and an Android mobile phone or Android Emulator that is run from Android Studio. The application also requires an API that is being used called Retrofit to fetch the data from the backend system. The mobile application is built by using Java language. On the other hand, for developing the backend system requires the code editor, which is Visual Studio Code. The data is currently stored in a hosting provider called ArdetaMedia. The backend system is built by using PHP and HTML language and Apache Web Server called XAMPP for creating a local web server for testing and deployment.

After the prototype is developed, it requires to be tested with several testing such as unit testing, integration testing, system testing, and user acceptance testing. Either mobile application or backend system needs to conduct these tests. The tests are carried out both from users and developer side.

Design of Experiments Slovin's formula is used to calculate the minimum respondents (sample size) that are needed to evaluate from the User Experience Questionnaire (UEQ). For calculating Slovin's formula, confidence level and population are required for having the sample size. The Slovin's formula can be calculated as shown in Equation 1:

$$
n=\frac{N}{1+N e^{2}}
$$

$\mathrm{n}=$ Number of samples

$\mathrm{N}=$ Total population

$\mathrm{e}=$ Error tolerance

The population size is 300 , from the average of visitors from Museum Wayang every week. The confidence level is at $80 \%$ and the sample size is: $\mathrm{n}$ $=\mathrm{N} /(1+\mathrm{N} * \mathrm{e} 2) \mathrm{n}=300 /(1+300 * 0.2 * 0.2) \mathrm{n}$ $=300 / 13 \mathrm{n}=23.07$. The sample size needs to be rounded becomes 24 people (Kalimba, 2016). Demography is also needed to evaluate the application (eTourGuide) such as gender, age, job, and nationality that might affect the ways of using the application. User Evaluation User evaluation is needed to check user's experience. User evaluation will be conducted after user tries the application. Filling the questionnaires is the method to gather the result after using the application. The questionnaire is based on Schrepp, et.al., (2017b).

\section{RESULT AND DISCUSSION}

The preliminary result for finding the most suitable beacon to implement the IoT technology is

$$
\text { Teknologi Informasi dan Komunikasi }
$$


Estimote beacon compare to Kontakt.io and iBKS beacons. The SDK from Estimote provides the logic to switch the device's screen between beacons' areas. Estimote also provides community and forum blogs to discuss the SDK. A lot of questions and answers about developing an application with Estimote can be found on those blogs. The beacon needs to be configured for placement inside the museum. The optimal configuration of the beacon depends the situation inside the museum. The configuration can be changed by the administrator easily through the beacon application.

As the case study, Museum Wayang has a concept like a labyrinth where the entrance and exit are just one-way path. This is quite beneficial because the application created requires a sequential process, so the user will not experience confusion. Museum Wayang also classifies the types of puppets along with others so the arrangement is not disorganized. It is just on the top floor of the museum where there are still some neatly arranged the description of objects. Museum Wayang has various types of puppets such as Wayang Kulit, Wayang Golek, Wayang Bambu, and Wayang Lidi. However, Wayang Kulit and Wayang Golek have a very large number compared to other puppets. This Puppet Museum does not only features puppets, but also gamelan, dolls, and masks. The information in the Museum Wayang is not complete yet, especially in English, which is mostly used by the foreigners.

There are several areas that have weak signal coverage in the museum. It means in some areas; the application is difficult to fetch the information related to the exhibits. However, there is a Wi-Fi connection that can be used to provide better internet connection for tourists or visitors. Furthermore, the application consists of the backend system for admin and the mobile application for the users. Changes and improvement might apply after software testing and user evaluation. Figure 5 shows the login page for accessing the backend system. Current login credential needs a password.

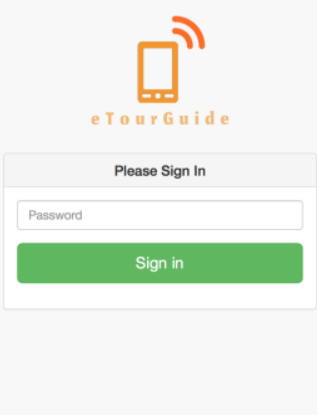

Figure 5 : Login to Backend System

Figure 6 shows the home page or the dashboard page that is used to configure the beacons with the objects. Admin can add, edit, and delete the configuration. Figure 7 shows the object description page for an object. Admin can configure the description for each wayang for multiple languages. The mobile application is developed in several stages. The purpose is to find the best layout that suits to users. 


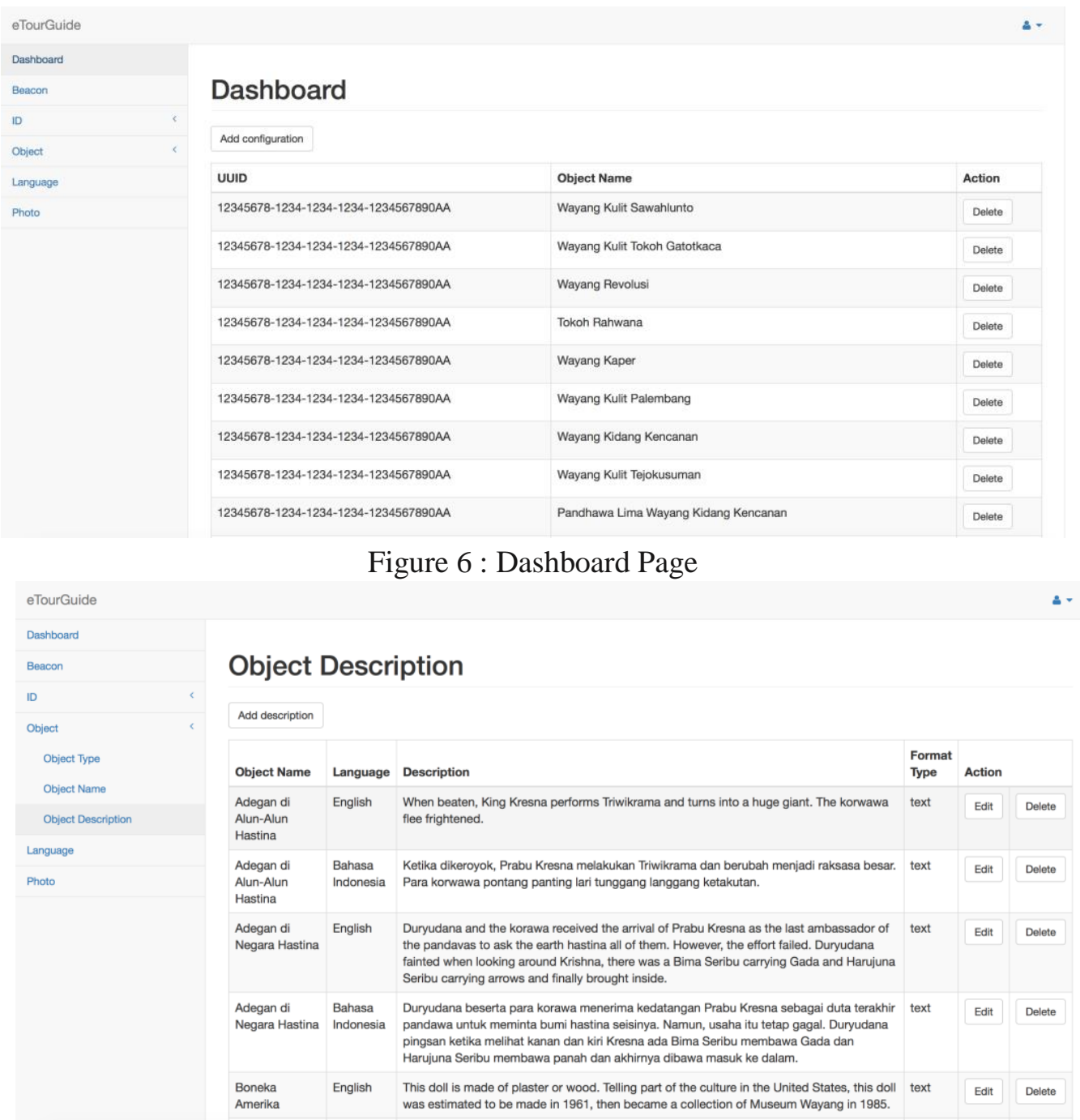

Figure 7 : Object Description Page
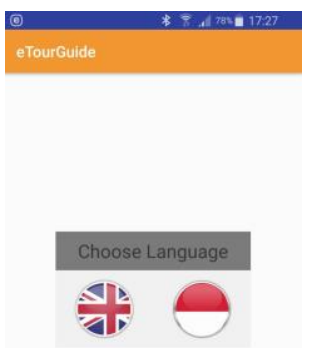

Figure 8 : Final Design for Choosing Language
Figure 8 shows the application gives user to choose the language first. The information will be provided based on the language from user choice. Figure 9 shows the list of objects after the application (eTourGuide) detects certain beacon. The objects will automatically change once the application detects another beacon from different area. Figure 10 shows the description of an object based on text type. The text size can be changed larger or smaller based on user expectation. The object may has more than one photo that can be slide to the left or right. Figure 11 shows the design for the description in video type. The video is fetched from Youtube URL. After

Teknologi Informasi dan Komunikasi 
developing and implementing the prototype, user evaluation is conducted.

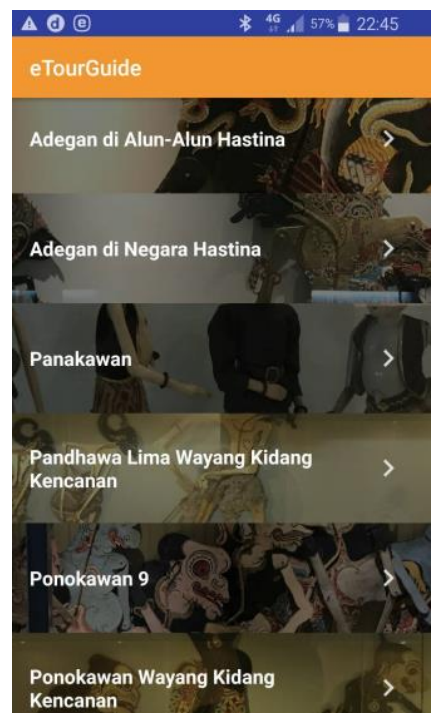

Figure 9 : Final Design for Displaying Objects

Table 1 shows the demographic of the gender that has used the application (eTourGuide), where the result is dominated by Male gender with $72.7 \%$. The survey result is dominated by the age of $22-37$ years old with $63.7 \%$. The survey result is dominated by Indonesian nationality with $63.7 \%$. Table 2 shows the result of the questionnaires for the application (eTourGuide). The graph consists of the range from -3 to +3 for every item from the questionnaires. The application (eTourGuide) gets a positive evaluation from the scale of perspicuity, efficiency and dependability (pragmatic quality) and stimulation and novelty (hedonic quality).

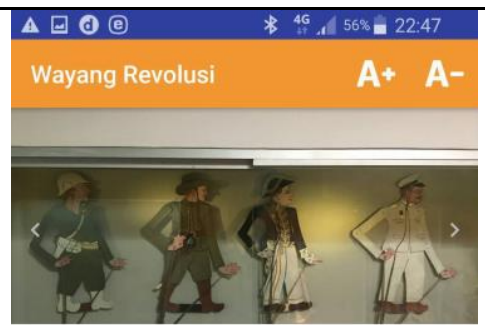

Wayang Revolusi

Wayang Kulit Revolusi (Wayang Suluh) is the idea and creation of Raden Mas Said, the Royal Poet of Surakarta Hadiningrat. This puppet describes the state of society during the Dutch colonial period. Expected to be made in 1936M. This puppet had been in the Netherlands for about 50 years. By various means and efforts, the puppets returned to Indonesia and were kept in the Wayang Museum in 2005.

Wayang Kulit Revolution: Dutch Military Aggression 1947-1948

Figure 10. Final Design for Text Description “

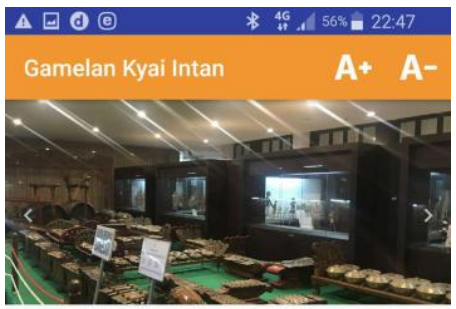

Gamelan Kyai Intan

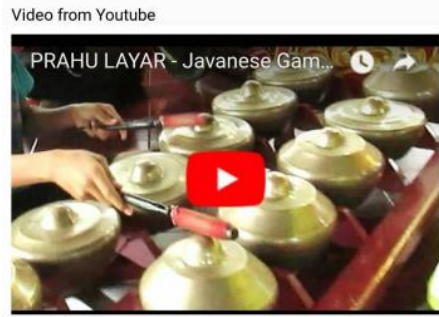

Figure 11 : Final Design for Video Description

Table 1 Result of the Demographic

\begin{tabular}{|c|l|l|}
\hline Demographic & \multicolumn{1}{|c|}{ Description } & Value \\
\hline \multirow{3}{*}{ Gender } & Male & 17 \\
\cline { 2 - 3 } & Female & 7 \\
\hline \multirow{4}{*}{ Age } & $<22$ years old & 3 \\
\cline { 2 - 3 } & 22-37 years old & 9 \\
\cline { 2 - 3 } & $38-53$ years old & 7 \\
\cline { 2 - 3 } & $>53$ years old & 5 \\
\hline Nationality & Indonesia & 18 \\
\hline
\end{tabular}

Teknologi Informasi dan Komunikasi 


\begin{tabular}{|l|l|l|}
\hline & Japan & 2 \\
\cline { 2 - 3 } & Australia & 1 \\
\cline { 2 - 3 } & Netherland & 1 \\
\cline { 2 - 3 } & Suriname & 1 \\
\cline { 2 - 3 } & China & 1 \\
\hline
\end{tabular}

Table 2 : Result from Mean Value per Item

\begin{tabular}{|c|c|c|}
\hline Aspects & Quality & $\begin{array}{l}\text { Mean } \\
\text { Value }\end{array}$ \\
\hline Supportive & \multirow{4}{*}{ Pragmative Quality } & +2.7 \\
\hline Easy & & +2.1 \\
\hline Efficient & & +2.4 \\
\hline Clear & & +2.2 \\
\hline Exciting & \multirow{4}{*}{ Hedonic Quality } & +2.3 \\
\hline Interesting & & +2.4 \\
\hline Inventive & & +2.5 \\
\hline Leading Edge & & +2.6 \\
\hline & Average Value & +2.4 \\
\hline
\end{tabular}

Furthermore, the Estimote SDK needs to be modified. The code makes the application (eTourGuide) to keep the connection to the closest distance of current beacon's signal. If the application detects other beacon's signal and the distance is closer than current beacon's signal, the application will switch the connection to the new beacon's signal. The original SDK from Estimote makes the application to detect all of the beacon's signal disorganizely. The distance is measured with Received Signal Strength Indication (RSSI) and measured transmit power. The RSSI and measured transmit power are calculated to compute the accuracy as shown in Figure 12. The result of the measurement can be interpreted as distance between mobile phone and the beacon.

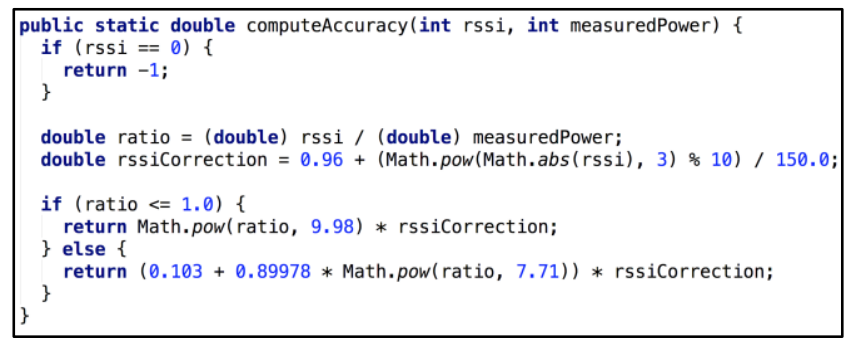

Figure 12 : Calculation to Measure the Signal Range
Table 3 Result of Experiments

\begin{tabular}{|l|l|}
\hline \multicolumn{1}{|c|}{ Experiments } & \multicolumn{1}{c|}{ Result } \\
\hline $\begin{array}{l}\text { Beacon's } \\
\text { temperature }\end{array}$ & $\begin{array}{l}\text { Doesn't effect to battery } \\
\text { life between } 20^{\circ} \mathrm{C}-40^{\circ} \mathrm{C}\end{array}$ \\
\hline Maximum Distance & \pm 70 meters \\
\hline $\begin{array}{l}\text { Disruption of the } \\
\text { signal }\end{array}$ & $\begin{array}{l}\text { - Any kind of solid objects } \\
\text { - Human body }\end{array}$ \\
\hline $\begin{array}{l}\text { Distance between 2 } \\
\text { Beacons }\end{array}$ & Keep the shortest distance \\
\hline $\begin{array}{l}\text { Detection Time to } \\
\text { detect Beacon }\end{array}$ & $\pm 3-8$ minutes \\
\hline $\begin{array}{l}\text { Beacon inside the } \\
\text { glass cabinet }\end{array}$ & Can be detected \\
\hline
\end{tabular}

Table 3 shows several experiments which are conducted to prove the experiments compatible with the theoretical side from related work and beacon's technical specification. Beacon's temperature is measured with the placement of the beacon inside the refrigerator and near the flamming stove to increase and decrease the temperature from $20^{\circ} \mathrm{C}-40^{\circ} \mathrm{C}$. The maximum distance is gathered by doing testing detection through an alley that has more than 70 meters long. Disruption of the signal is done by placing any kind of object to block the signal between beacon and the mobile phone. Experiment for distance between two beacons is conducted by placing the mobile phone between two beacons, and move the mobile phone to the beacon and the other one. Detection time to detect beacon is measured when the mobile application scans the beacon signal. Switching the beacon's signal to the shortest distance can be done also by moving the mobile phone towards certain beacon and calculate the time to detect the beacon's current signal. Putting the beacon inside the glass cabinet making the beacon's signal can still be detected by the mobile application.

Table 4 Effects from the Experiments

\begin{tabular}{|l|l|}
\hline \multicolumn{1}{|c|}{ Experiments } & \multicolumn{1}{c|}{ Result } \\
\hline $\begin{array}{l}\text { Beacon's } \\
\text { temperature }\end{array}$ & $\begin{array}{l}\text { Placement of beacon inside } \\
\text { the museum }\end{array}$ \\
\hline $\begin{array}{l}\text { Maximum } \\
\text { distance }\end{array}$ & Placement between beacons \\
\hline
\end{tabular}

Teknologi Informasi dan Komunikasi 


\begin{tabular}{|l|l|}
\hline $\begin{array}{l}\text { Disruption of the } \\
\text { signal }\end{array}$ & $\begin{array}{l}\text { Beacon placement must high } \\
\text { enough }\end{array}$ \\
\hline $\begin{array}{l}\text { Distance between } \\
2 \text { beacons }\end{array}$ & $\begin{array}{l}\text { Shortest distance to beacon } \\
\text { for showing the information }\end{array}$ \\
\hline $\begin{array}{l}\text { Detection time to } \\
\text { detect beacon }\end{array}$ & $\begin{array}{l}\text { Calculate the speediness of } \\
\text { the application }\end{array}$ \\
\hline $\begin{array}{l}\text { Beacon inside the } \\
\text { glass cabinet }\end{array}$ & $\begin{array}{l}\text { Can be placed inside together } \\
\text { with the collections }\end{array}$ \\
\hline
\end{tabular}

Table 4 shows the effects from the experiments that have been conducted. Result from the experiments might affect further development or implementation inside the museum. The effects for further purposes are currently based on the situation inside the museum.

\section{CONCLUSION}

The mobile application (eTourGuide) has been developed to increase user experience when visiting into a museum. This research is conducted to prove that an Internet of Things based mobile application (eTourGuide) can satisfy tourists experience in getting the information interestingly and interactively. This implementation also develops a mobile application that uses a location-based service that can make tourists easier to get information about the content inside a museum in multiple languages. The user evaluation questionnaire concludes the experience result from every user that uses the eTourGuide. The result of the questionnaire from users concludes eight aspects of evaluation with the positive result from the aspects.

\section{ACKNOWLEDGMENT}

Thank you to Head and all the members of Museum Wayang who have allowed us to provide the opportunity to do the application testing.

\section{REFERENCE}

Barapatre, A. . S. et al. (2017) 'Smart College System using IoT BLE Beacons', Ijarcce, 6(4), pp. 438-442. doi: 10.17148/IJARCCE.2017.6485.

Bernstein, S. (2015) The Realities of Installing iBeacon to Scale. Available at: https://www.brooklynmuseum.org/community/ blogosphere/2015/02/ 04/the-realities- ofinstallingibeacon-to-scale/ (Accessed: 6 December 2017).

Cayo Indonesia. (n.d.). Rangkuman Sembilan program (Nawa Cita) Jokowi-JK. [online] Available at: http://www.indonesiacayo.com/2017/06/rangk uman-sembilan- program-nawa-cita.html [Accessed 13 Jan. 2018].

Compare beacons (no date). Available at: https://estimote.com/products/ (Accessed: 3 December 2017).

Cucini, A. and Forconi, S. (2016) 'BLE beacons, Eddystone and Physical Web : an introduction'.

Cygnet-infotech, (n.d.) 'Beacon Mobile Application For Museums With Extensive In-House Location Based Features And Custom CMS'. Available at: http://www.cygnetinfotech.com/media/581445/beacon-mobile-

application-for-museum.pdf (Accessed: 6 December 2017).

Doljenkova, V. and Tung, G. (2015) Beacons: Exploring Location- Based Technology in Museums. Available at: https://www.metmuseum.org/blogs/digitalunderground/2015/beacons (Accessed: 6 December 2017).

Gallagher, S. (2016) 'What You Need to Know About', Harvard Business Review, (April), pp. 121-130. doi: 10.109/01.orn.0000407780.43380.20.

Gąsiorek, A. (2015) Beacons at Kew Gardens Save $90+\%$ over WiFi for Proximity Engagement. Available at: https://kontakt.io/blog/beacons-at-kewgardens-usecase/ (Accessed: 6 December 2017).

Investments, I. (n.d.). Tourism in Indonesia: 15 Million Foreign Tourists in 2017?| Indonesia Investments. [online] Indonesia- investments.com. Available at: https://www.indonesiainvestments.com/id/culture/culturecolumns/tourismin-indonesia- 15-millionforeign-tourists-in2017/item7949? [Accessed 13 Jan. 2018].

IoT Agenda. (2016). What is Internet of

Teknologi Informasi dan Komunikasi 
Things (IoT)? - Definition from WhatIs.com. [online] Available at:

http://internetofthingsagenda.techtarget.com/d efinition/Internet- of- Things-IoT [Accessed 13 Jan. 2018].

Laugwitz, B., Held, T. and Schrepp, M. (2008) 'Construction and evaluation of a user experience questionnaire', Proceedings of the 4th Symposium of the Workgroup HumanComputer Interaction and Usability Engineering of the Austrian Computer Society (USAB'08), 5298, pp. 63-76. doi: 10.1007/978-3-540-89350-9_6.

Schrepp, M. and Hinderks, A. (2014) 'Design, User Experience, and Usability. Theories, Methods, and Tools for Designing the User
Experience', 8517(June). doi: 10.1007/978-331907668-3.

Schrepp, M., Hinderks, A. and Thomaschewski, J. (2017a) 'Construction of a Benchmark for the User Experience Questionnaire (UEQ)', International Journal of Interactive Multimedia and Artificial Intelligence, 4(4), p. 40. doi: 10.9781/ijimai.2017.445.

Schrepp, M., Hinderks, A. and Thomaschewski, J. (2017b) 'Design and Evaluation of a Short Version of the User Experience Questionnaire (UEQ-S)', International Journal of Interactive Multimedia and Artificial Intelligence, 4(6), p. 103. doi: 10.9781/ijimai.2017.09.001. 